\title{
The optimal effect-site concentration of remifentanil to attenuate the pain caused by propofol
}

\author{
Jong-Yeon Lee, HyeonJeong Yang, Seok Hwan Choi, Dong Wook Shin, Seung-Ki Hong, and \\ Duk-Hee Chun
}

Department of Anesthesiology and Pain Medicine, CHA Bundang Medical Center, CHA University, Seongnam, Korea

Background: The injection pain of propofol is a frequent and well-known adverse effect. This study was designed to determine the optimal effect-site concentration of remifentanil for minimizing injection pain during induction with propofol.

Methods: A total intravenous anesthetic technique was used for patients undergoing general anesthesia and remifentanil was pretreated to reach a certain target concentration before propofol injection. Using Dixon's up-anddown method, the degree of pain described by the patient was used to adjust the target concentration of remifentanil for the next patient. Ten success-failure curves (crossovers) were sought to find the effect-site concentration (EC) of remifentanil for minimizing injection pain of propofol.

Results: The $\mathrm{EC}$ of remifentanil in $50 \%$ and $95 \%$ of adult female population $\left(\mathrm{EC}_{50}\right.$ and $\left.\mathrm{EC}_{95}\right)$ for minimizing injection pain of propofol were $3.09 \mathrm{ng} / \mathrm{ml}$ (95\% confidence limits [CI] 2.92-3.30 ng/ml) and $3.78 \mathrm{ng} / \mathrm{ml}$ (95\% CI 3.45-3.95 $\mathrm{ng} / \mathrm{ml}$ ), respectively. Clinically significant hemodynamic compromise or respiratory complications were not found during remifentanil infusion.

Conclusions: Maintaining $3.78 \mathrm{ng} / \mathrm{ml} \mathrm{EC}$ of remifentanil during induction with propofol attenuate propofol injection pain without serious adverse events in female patients undergoing general anesthesia and this method may provide the patient's comfort without preparing other drugs for pain relief. (Korean J Anesthesiol 2012; 63: 108-112)

Key Words: Effect-site concentration, Propofol, Remifentanil.

Received: February 8, 2012. Revised: March 17, 2012. Accepted: March 23, 2012.

Corresponding author: Duk-Hee Chun, M.D., Department of Anesthesiology and Pain Medicine, CHA Bundang Medical Center, CHA University, 351, Yatap-dong, Bundang-gu, Seongnam 463-712, Korea. Tel: 82-31-780-5643, Fax: 82-31-701-9433, E-mail: leah1013@chamc.co.kr (c) This is an open-access article distributed under the terms of the Creative Commons Attribution Non-Commercial License (http:// creativecommons.org/licenses/by-nc/3.0/), which permits unrestricted non-commercial use, distribution, and reproduction in any medium, provided the original work is properly cited. 


\section{Introduction}

Pain on injection is one of the main disadvantages of propofol during induction of anesthesia. The incidence of pain on injection is reported to vary between $28 \%$ and $90 \%$ in adults $[1,2]$. Many techniques have been suggested to prevent the pain but several investigators have reported that administering remifentanil via bolus injection or continuous infusion can effectively reduce pain associated with propofol injection [3-6].

Target controlled infusion (TCI) system is a computerassisted system for intravenous administration of anesthetics, and is becoming a part of routine anesthesia technique. Remifentanil is an opioid with a rapid onset, an ultrashort duration of action, and a stable, short context-sensitive half-time compared with other opioids [7]. Because of these advantages of remifentanil, it has often been used as a TCI combined with propofol for induction and maintenance of anesthesia.

Therefore we used a TCI system to find the optimal effectsite concentration (EC) of remifentanil in $50 \%$ and $95 \%$ of adult female population $\left(\mathrm{EC}_{50}\right.$ and $\mathrm{EC}_{95}$ ) for minimizing injection pain of propofol using the Dixon's up-and-down method.

\section{Materials and Methods}

After approval from the institutional ethics committee, written informed consent was obtained from 31 patients (all females, ASA I-II, aged 19-64 years undergoing general anesthesia for elective surgery) who were enrolled in this study. We excluded all patients with difficult venous access, those with known allergy to egg lecithin or soybean oil, severe neurological deficits, or psychiatric disorders, and habituation to analgesics, sedatives or anti-anxiety drugs.

None of the patients was premedicated before entering the operating room. An 18 gauge venous cannula was placed in each patient's forearm and lactated Ringer's solution was started as infusion. The infusions of propofol and remifentanil were prepared using fresofol $2 \%$ inj., $50 \mathrm{ml}$ vial (Fresenius Kabi, Austria) and Ultiva ${ }^{\text {TM }}$ inj., 1 mg vial (GlaxoSmithKline, Italy), respectively. The infusion port for propofol and remifentanil was connected, as close as possible, to the intravenous catheter to minimize dead space. Standard monitoring consisted of pulse oximetry, ECG, and noninvasive blood pressure. A TCI pump (Orchestra ${ }^{\circledR}$ Base Primea, Fresenius Vial, France) was used for effect site TCI of propofol and remifentanil. We used the Marsh et al. [8] and Minto et al. [9] models for propofol and remifentanil, respectively.

All patients were preoxygenated for 5 min using a facemask. The target EC of remifentanil concentration for the first patient was set at $3.0 \mathrm{ng} / \mathrm{ml}$ with a maximal flow rate limited of 450 $\mathrm{ml} / \mathrm{h}$. During remifentanil injection, remifentanil related com- plications were assessed by repeated observation and verbal questions until the target EC of remifentanil was reached. Patient complications included the following: hypotension ( $>20 \%$ decrease compared with baseline value), bradycardia (heart rate $<45$ beats $/ \mathrm{min}$ ), chest wall rigidity (expressed as chest tightness and difficulty in breathing), desaturation $\left(\mathrm{SpO}_{2}\right.$ $<95 \%$ ), dizziness, nausea, cough, pruritus, and erythema.

When the intended target EC of remifentanil was reached, TCI of propofol was started at a target EC of $3.5 \mu \mathrm{g} / \mathrm{ml}$ with maximal flow rate limited to $450 \mathrm{ml} / \mathrm{h}$. During propofol injection, the patients were repeatedly asked questions regarding comfort of the injection until loss of consciousness. An investigator blinded to the patients' EC of remifentanil evaluated propofol induced pain using a verbal rating scale: none (negative response to questioning), mild pain (pain reported only in response to questioning), moderate pain (spontaneous verbal expression of pain without grimacing or withdrawal of arm occurred), severe pain (strong vocal response with facial grimacing, arm withdrawal, or tears) [3]. The infusions of propofol and remifentanil were continued until the patient fell asleep and tracheal intubation was facilitated by rocuronium 0.6 $\mathrm{mg} / \mathrm{kg}$. The patients were mechanically ventilated with oxygen and air, and anesthesia was maintained using the TCI system.

For each subsequent patient, the target EC of remifentanil was determined by the response of the previous patient using the Dixon's up-and-down method. If a patient had none to mild pain during propofol injection, the target EC of remifentanil for the subsequent patient was decreased by $0.5 \mathrm{ng} / \mathrm{ml}$. If a patient had moderate to severe pain, the target EC of remifentanil was increased by $0.5 \mathrm{ng} / \mathrm{ml}$.

The Dixon's up-and-down method needs minimum of 6 pairs of success-failure for statistical analysis [10]. This study ended when data of 10 independent pairs (success-failure crossovers) of patients had been collected. The $\mathrm{EC}_{50}$ and $\mathrm{EC}_{95}$ of remifentanil and their confidence intervals were calculated from the isotonic regression estimators and 9,999 bootstrap replications. Hemodynamic data changes were compared by repeated measures ANOVA. All statistical calculations were performed using the SPSS version 17.0 for Windows (SPSS Inc, IL, USA) and R version 2.11.0 (R foundations for Statistical Computing, Vienna, Austria). $\mathrm{P}<0.05$ was considered statistically significant.

\section{Results}

Thirty-one female patients aged 19-64 years were enrolled in this study. Fig. 1 shows individual concentration-responses according to the up-and-down sequence. From the isotonic regression analysis and bootstrap distribution, the $\mathrm{EC}_{50}$ of remifentanil for minimizing injection pain of propofol was $3.09 \mathrm{ng} /$ 
$\mathrm{ml}(95 \% \mathrm{CI} 2.92-3.30 \mathrm{ng} / \mathrm{ml})$ and the $\mathrm{EC}_{95}$ was $3.78 \mathrm{ng} / \mathrm{ml}(95 \%$ CI $3.45-3.95 \mathrm{ng} / \mathrm{ml})$.

Significant respiratory complications such as bradycardia, hypotension, or oxygen desaturation did not occur in any of the patients. However, one patient coughed and 11 patients complained of dizziness during remifentanil administration without requiring treatment.

Hemodynamic data of patients are shown in Table 1. Mean arterial pressure (MAP) after remifentanil infusion was significantly lower compared with the baseline value $(\mathrm{P}=0.001)$. However, there were no patients with clinically significant hypotension requiring treatment. Heart rate did not change significantly after remifentanil or propofol infusion.

\section{Discussion}

In this study, we used propofol-remifentanil TCI to find the EC of remifentanil to minimize injection pain during induction with propofol. Our results show that the $\mathrm{EC}_{95}$ of remifentanil that minimize propofol injection pain is $3.78 \mathrm{ng} / \mathrm{ml}$ (95\% CI 3.45-

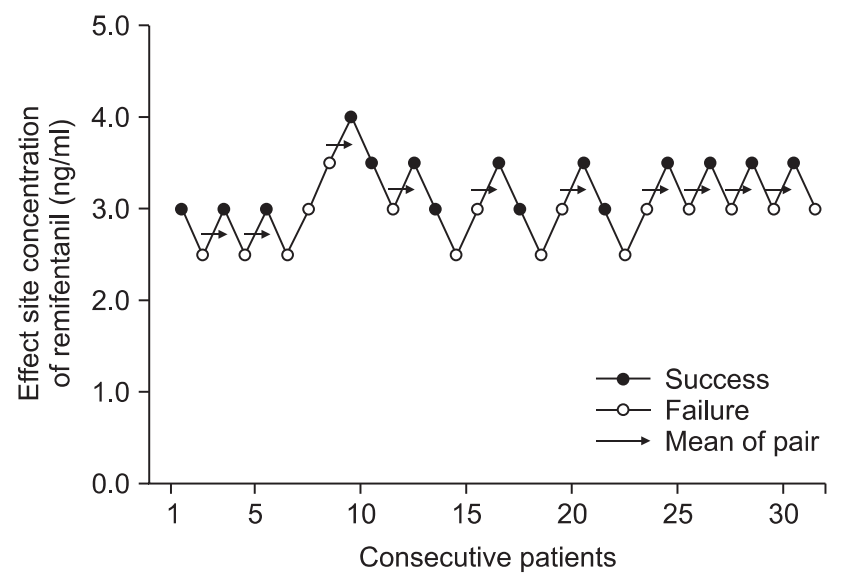

Fig. 1. The responses of 31 consecutive patients to propofol injection and a dose of remifentanil. The arrow indicates the midpoint of the effect site concentration of all independent pairs of patients that achieved crossover (i.e., failure $[\bigcirc]$ to success [O]).
$3.95 \mathrm{ng} / \mathrm{ml}$ ) without causing clinically significant hypotension or bradycardia.

Propofol is a popular intravenous anesthetic induction agent. However, the local pain experienced during intravenous administration of propofol remains a problem. The precise mechanism of this pain is not clearly understood. However, many factors that affect pain on injection are evaluated, including the speed of injection, speed of i.v. carrier fluid, the buffering effect of blood, peripheral i.v. site, and the intrinsic drug properties [11-15]. A variety of strategies have been tried to reduce the pain caused by propofol by employing premedication [16], cooling of the propofol solution [17], pretreatment with ketamine [18], local anesthetics [19], and opioids [4,5].

Since pretreatment with opioids has been reported to reduce the incidence and severity of pain during a propofol injection, several investigators have studied the use of remifentanil to prevent the pain of propofol injection [3-6]. Remifentanil was effective comparable with lidocaine [3,20,21], sufentanil [22], and alfentanil $[5,23]$. Also the incidence of propofol injection pain was reduced by $50 \%$ when a remifentanil $0.25 \mathrm{ug} / \mathrm{kg} /$ min was administered before propofol [3], 10 and $20 \mu \mathrm{g}$ of remifentanil achieved reduction of propofol injection pain [5], and pretreatment with remifentanil by EC of $4.0 \mathrm{ng} / \mathrm{ml} \mathrm{did}$ reduce propofol injection pain without causing severe adverse events [6].

Total intravenous anesthesia (TIVA) is a widely used technique, because of the high quality of anesthesia, rapid immediate recovery, and few side effects [24,25]. It is possible to reach and to maintain a defined target concentration of drugs using a TCI system, because it determines the initial loading dose needed to achieve the required target concentration and the infusion rate needed to maintain it at constant [26]. Remifentanil is a suitable adjunct to propofol for TIVA because it can be infused continuously during procedures regarding its excellent analgesic effect, rapid onset and offset of action owing to a short context sensitive half-time $[7,25]$. In addition, remifentanil is found to be very potent in preventing moderate and severe propofol injection pain [3]. However, some

Table 1. Changes in Blood Pressure and Heart Rate in Patients

\begin{tabular}{|c|c|c|c|c|}
\hline & $\begin{array}{c}\text { MAP } \\
(\mathrm{mmHg})\end{array}$ & $P$ value & $\begin{array}{c}\text { HR } \\
\text { (beats/min) }\end{array}$ & $P$ value \\
\hline Baseline & $91.8 \pm 9.6$ & & $69.8 \pm 11.3$ & \\
\hline After remifentanil infusion & $88.3 \pm 9.7$ & 0.001 & $67.5 \pm 14.4$ & 0.466 \\
\hline After both infusion & $76.3 \pm 13.2$ & & $66.3 \pm 10.0$ & \\
\hline Compared with baseline value & & $<0.001$ & & 0.082 \\
\hline Compared with after remifentanil infusion value & & $<0.001$ & & 1.000 \\
\hline
\end{tabular}

Values are expressed as mean \pm SD. MAP: mean arterial blood pressure, HR: heart rate, Baseline: on arrival in the operating room, After remifentanil infusion: after effect-site concentration of remifentanil was reached, After both infusion: after effect-site concentration of both remifentanil and propofol reached target concentration. 
investigators are reluctant to use remifentanil as a bolus injection because of the side effects of an opioid, which includes bradycardia, hypotension, chest wall rigidity, and desaturation. Therefore, we tried to find the $\mathrm{EC}_{50}$ and $\mathrm{EC}_{95}$ of remifentanil for minimizing injection pain of propofol and investigated for complications associated with remifentanil administration in patients undergoing general anesthesia using a TCI pump.

Even though remifentanil shares common properties of the opioid drugs, such as effective, dose-related analgesia, and respiratory depression, none of the patients suffered hypoventilation or desaturation at the EC of remifentanil we administered. Although dizziness was noted in 11 patients, this did not result in problems. MAP did decrease after remifentanil and propofol reached target concentration, but hemodynamic stability was maintained and targeted EC of remifantanil did not seem to cause significant hemodynamic disturbance.

There are some limitations to the present study. First, we did not measure plasma concentrations of remifentanil. Rather, we used a predicted value using Minto's pharmacokinetic model with an acceptable level of bias and inaccuracy [27]. Second, age variation should be considered because older patients are more sensitive to opioids. Third, the study population is limited to females. However, since there is no gender difference in the incidence of pain on propofol injection [28], this data should be generalizable to a male population as well.

In conclusion, the $\mathrm{EC}_{95}$ of remifentanil for minimizing injection pain of propofol was $3.78 \mathrm{ng} / \mathrm{ml}$. Maintaining this EC of remifentanil during induction with propofol reduced propofol injection pain without serious adverse events in patients undergoing general anesthesia and this method may provide the patient with comfort without preparing other drugs for pain relief.

\section{References}

1. Mangar D, Holak EJ. Tourniquet at $50 \mathrm{~mm}$ Hg followed by intravenous lidocaine diminishes hand pain associated with propofol injection. Anesth Analg 1992; 74: 250-2.

2. Stark RD, Binks SM, Dutka VN, O'Connor KM, Arnstein MJ, Glen JB. A review of the safety and tolerance of propofol ('Diprivan'). Postgrad Med J 1985; 61 Suppl 3: 152-6.

3. Roehm KD, Piper SN, Maleck WH, Boldt J. Prevention of propofolinduced injection pain by remifentanil: a placebo-controlled comparison with lidocaine. Anaesthesia 2003; 58: 165-70.

4. Basaranoglu G, Erden V, Delatioglu H, Saitoglu L. Reduction of pain on injection of propofol using meperidine and remifentanil. Eur J Anaesthesiol 2005; 22: 890-2.

5. Iyilikci L, Balkan BK, Gokel E, Gunerli A, Ellidokuz H. The effects of alfentanil or remifentanil pretreatment on propofol injection pain. J Clin Anesth 2004; 16: 499-502.

6. Lee JR, Jung CW, Lee YH. Reduction of pain during induction with target-controlled propofol and remifentanil. Br J Anaesth 2007; 99: 876-80.

7. Egan TD, Minto CF, Hermann DJ, Barr J, Muir KT, Shafer SL. Remifentanil versus alfentanil: comparative pharmacokinetics and pharmacodynamics in healthy adult male volunteers. Anesthesiology 1996; 84: 821-33.

8. Marsh B, White M, Morton N, Kenny GN. Pharmacokinetic model driven infusion of propofol in children. Br J Anaesth 1991; 67: 41-8.

9. Minto CF, Schnider TW, Egan TD, Youngs E, Lemmens HJ, Gambus $\mathrm{PL}$, et al. Influence of age and gender on the pharmacokinetics and pharmacodynamics of remifentanil. I. Model development. Anesthesiology 1997; 86: 10-23.

10. Dixon WJ. Staircase bioassay: the up-and-down method. Neurosci Biobehav Rev 1991; 15: 47-50.

11. Scott RP, Saunders DA, Norman J. Propofol: clinical strategies for preventing the pain of injection. Anaesthesia 1988; 43: 492-4.

12. Klement W, Arndt JO. Pain on injection of propofol: effects of concentration and diluent. Br J Anaesth 1991; 67: 281-4.

13. Kang HJ, Kwon MY, Choi BM, Koo MS, Jang YJ, Lee MA. Clinical factors affecting the pain on injection of propofol. Korean $\mathrm{J}$ Anesthesiol 2010; 58: 239-43.

14. Larsen B, Beerhalter U, Biedler A, Brandt A, Doege F, Brun K, et al. Less pain on injection by a new formulation of propofol? A comparison with propofol LCT. Anaesthesist 2001; 50: 842-5.

15. Sim JY, Lee SH, Park DY, Jung JA, Ki KH, Lee DH, et al. Pain on injection with microemulsion propofol. Br J Clin Pharmacol 2009; 67: 316-25.

16. Fragen RJ, de Grood PM, Robertson EN, Booij LH, Crul JF. Effects of premedication on diprivan induction. Br J Anaesth 1982; 54: 913-6.

17. McCrirrick A, Hunter S. Pain on injection of propofol: the effect of injectate temperature. Anaesthesia 1990; 45: 443-4.

18. Saadawy I, Ertok E, Boker A. Painless injection of propofol: pretreatment with ketamine vs thiopental, meperidine, and lidocaine. Middle East J Anesthesiol 2007; 19: 631-44.

19. Gehan G, Karoubi P, Quinet F, Leroy A, Rathat C, Pourriat JL. Optimal dose of lignocaine for preventing pain on injection of propofol. Br J Anaesth 1991; 66: 324-6.

20. Kwak K, Kim J, Park S, Lim D, Kim S, Baek W, et al. Reduction of pain on injection of propofol: combination of pretreatment of remifentanil and premixture of lidocaine with propofol. Eur J Anaesthesiol 2007; 24: 746-50.

21. Aouad MT, Siddik-Sayyid SM, Al-Alami AA, Baraka AS. Multimodal analgesia to prevent propofol-induced pain: pretreatment with remifentanil and lidocaine versus remifentanil or lidocaine alone. Anesth Analg 2007; 104: 1540-4.

22. Honarmand A, Safavi M. Prevention of propofol-induced injection pain by sufentanil: a placebo-controlled comparison with remifentanil. Clin Drug Investig 2008; 28: 27-35.

23. Rahman Al-Refai A, Al-Mujadi H, Petrova Ivanova M, Marzouk HM, Batra YK, Al-Qattan AR. Prevention of pain on injection of propofol: a comparison of remifentanil with alfentanil in children. Minerva Anestesiol 2007; 73: 219-23.

24. Glass PS, Gan TJ, Howell S. A review of the pharmacokinetics and pharmacodynamics of remifentanil. Anesth Analg 1999; 89(4 Suppl): S7-14.

25. Westmoreland CL, Hoke JF, Sebel PS, Hug CC Jr, Muir KT. Phar- 
macokinetics of remifentanil (GI87084B) and its major metabolite (GI90291) in patients undergoing elective inpatient surgery. Anesthesiology 1993; 79: 893-903.

26. Guarracino F, Lapolla F, Cariello C, Danella A, Doroni L, Baldassarri $\mathrm{R}$, et al. Target controlled infusion: TCI. Minerva Anestesiol 2005; 71:335-7.
27. Mertens MJ, Engbers FH, Burm AG, Vuyk J. Predictive performance of computer-controlled infusion of remifentanil during propofol/ remifentanil anaesthesia. Br J Anaesth 2003; 90: 132-41.

28. Tan $\mathrm{CH}$, Onsiong MK. Pain on injection of propofol. Anaesthesia 1998; 53: 468-76. 